
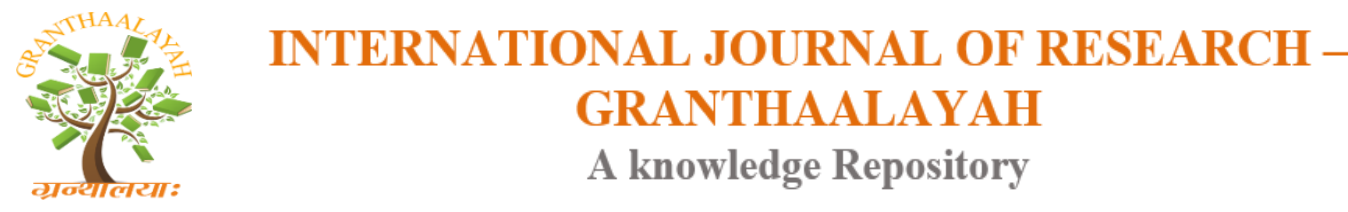

Management

\title{
THE POSSIBILITIES OF REDUCING THE FUEL CONSUMPTION BY COVERING THE LOADING CAPACITY OF TIPPING SEMI-TRAILER DESIGNED TO CARRY BULK MATERIALS
}

\author{
František Synák ${ }^{* 1}$, Vladimír Rievaj ${ }^{1}$, Monika Kiktová ${ }^{1}$, Tomasz Figlus ${ }^{2}$ \\ ${ }^{1}$ Department of Road and Urban Transport, The Faculty of Operation and Economics of \\ Transport and Communications, University of Zilina, Slovakia \\ ${ }^{2}$ Department of Automotive Vehicle Construction, Faculty of Transport, The Silesian University \\ of Technology, Poland
}

\begin{abstract}
The amount of fossil fuels consumed has direct impact on global pollution and health status of the human population. An increasing amount of fuel consumed leads to the increase using of non-renewable resources of energy. This article deals with possibilities of reducing the fuel consumption by covering the loading capacity of tipping semi-trailer. The introduction of this paper describes the impact the amount of fuel consumed on production of carbon dioxide. The ratio of driving resistances to fuel consumption is shown in the graph. In the second part of the article there is the methodology of the measurements. The measurements were conducted by driving test. The fuel consumption of tipping semi-trailer was measured during the driving with uncovered and covered loading capacity. The importance of this paper lies in the quantified the possibilities of reducing the fuel consumption by covering the loading capacity of tipping semitrailer designed to carry bulk materials.
\end{abstract}

Keywords: Air Resistance; Carbon Dioxide; Driving Resistance; Fuel Consumption; Global Pollution; Tipping Semi-Trailer.

Cite This Article: František Synák, Vladimír Rievaj, Monika Kiktová, and Tomasz Figlus. (2018). "THE POSSIBILITIES OF REDUCING THE FUEL CONSUMPTION BY COVERING THE LOADING CAPACITY OF TIPPING SEMI-TRAILER DESIGNED TO CARRY BULK MATERIALS." International Journal of Research - Granthaalayah, 6(1), 455-462. https://doi.org/10.29121/granthaalayah.v6.i1.2018.1654.

\section{Introduction}

Consuming of the fossil fuels leads to the use of non-renewable resources of energy as well as to the production of gaseous emissions [1]. The main emphasis is placed on the production of carbon dioxide [2] which is considered to be the main greenhouse gas [3]. The production and consumption of 11 of diesel oil lead to the production of $3,251 \mathrm{~g}$ of $\mathrm{CO}_{2}$ [4]. Thus, the amount of fuel consumed has direct impact on the production of carbon dioxide. Transport is 
the only industry in European Union in which there is not the reduction of $\mathrm{CO}_{2}$ production but its increase when concerning the long term. Trucks and buses are producers of $6 \%$ of $\mathrm{CO}_{2}$ within the framework of European Union [5]. Current ecological situation requires measures to ensure the reduction of the fuel consumption also followed by the production of emissions. Such goals would be easily reached by reducing of the transport services. However, together with increasing demands of life and trade globalization in industry, it will not be able achieve the reduction of services, indeed it will be quite opposite [6]. The second option supported also by the legislative could be seen in the replacement of the vehicles with combustion engine by the vehicles with electric motor [7]. Such solution would bring about the reduction of $\mathrm{CO}_{2}$ emissions in the area of vehicle operation, however, within the framework of European Union as a whole it would bring about the increase of $\mathrm{CO}_{2}$ emissions. The effect would be caused by the fact that LCA emission factor for the production of electrical power within the countries of European Union is $0.578 \mathrm{t}$ $\mathrm{CO}_{2}$-eq. $\mathrm{MWh}_{\mathrm{e}}{ }^{-1}$. When counting the average efficiency of an electric car which is $85 \%$, the value is $0.680 \mathrm{CO}_{2}$-eq.MWhe ${ }^{-1}$. For the production and consumption of diesel oil, there is LCA factor with the value of $0.305 \mathrm{t} \mathrm{CO} 2$-eq.MWh diesel $^{-1}$ [8].

If there is not possible to reduce the amount of services and the implementation of electric cars at the current course of the production of electrical power would bring about the increase of $\mathrm{CO}_{2}$ production, it is necessary to focus on the realisation of transport services with the highest possible efficiency [9] and, thus, with the lowest amount of fuel consumed per p/km, or t/km. Reducing of the fuel consumption under the condition that there is transported the same number of goods or people can be provided by two main ways. The first way is to improve the engine [10]. The second way is to reduce the value of the driving resistances [11]. A vehicle, in order to overcome the driving resistances, needs a certain engine power [12]. To produce such engine power it is necessary to consume a certain amount of fuel. The intensity of driving resistances has therefore an impact on the fuel consumed as well as on the amount of carbon dioxide produced [13]. The driving resistances are the rolling resistance that always acts against the direction of travel [12], the air resistance that also acts against the direction of travel [14] and the internal mechanical vehicle resistances [15]. Other resistance is the inertia resistance that acts against the direction of travel in case that a vehicle accelerates, and acts in the direction of travel in case that a vehicle decelerates. A vehicle overcomes the gradient resistance when the road surface is not flat [16].

The process of an engine power needed for overcoming the driving resistances of an articulated vehicle is displayed in the Fig. 1

The calculation was made under these conditions:

The mass: $40,000 \mathrm{~kg}$

The size of the frontal area: $9.18 \mathrm{~m}^{2}$

Air resistance coefficient: 0.68

Air density: $1.29 \mathrm{~kg} \cdot \mathrm{m}^{-3}$

Losses in gear: $10 \%$

Rolling resistance coefficient: 0.006

Road surface gradient: $0^{\circ}$ 


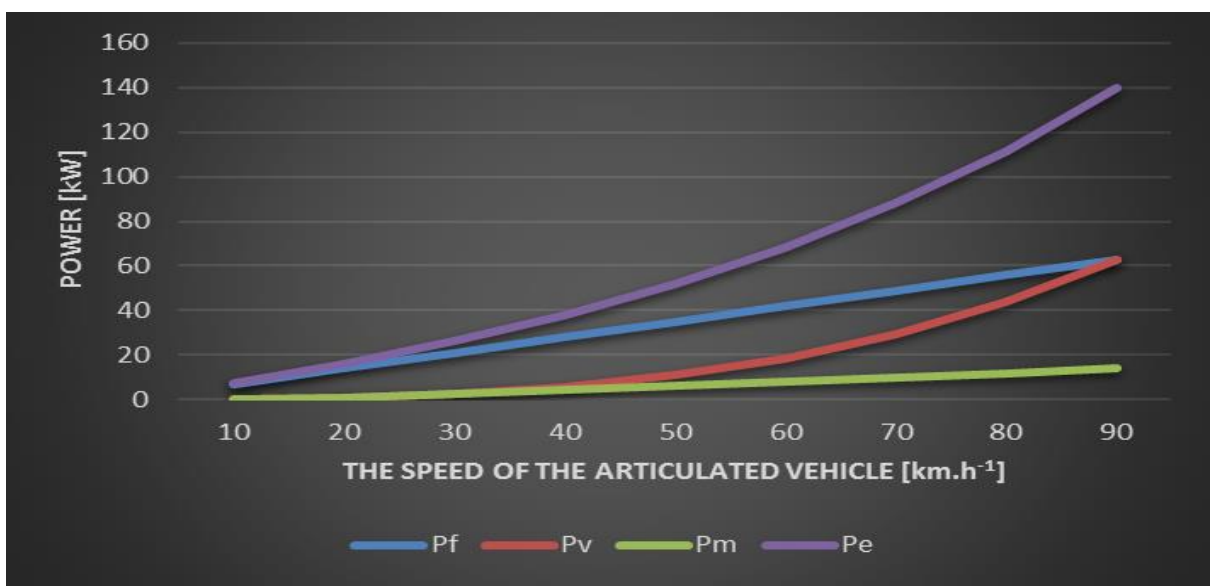

Figure 1: Powers of articulated vehicle [authors]

The curves express the process of engine power needed for overcoming a certain driving resistance:

$\mathrm{P}_{\mathrm{f}}$, blue curve - rolling resistance,

$\mathrm{P}_{\mathrm{v}}$, red curve - air resistance,

$P_{m}$, green curve - internal resistances

$\mathrm{P}_{\mathrm{e}}$, purple curve - the sum of all driving moments.

As shown in the Fig. 1, the engine power needed for overcoming the air resistance at the speed of $90 \mathrm{~km} . \mathrm{h}-1$ reaches approximately the same value as the engine power needed for overcoming the rolling resistance. In practice, the air resistance has in many cases larger share in the engine power needed as well as in the amount of fuel consumed. Since the average loading of an articulated vehicle represents $64 \%$ [17], that is the overall vehicle mass of $30 \mathrm{t}$, we can see that the mass reduction will also lead to the reduction of value of the rolling resistance.

The paper's objective is to measure the impact of covering the loading capacity of tipping semitrailer on the fuel consumption. There is a presumption that such covering leads to the reduction of the air resistance and, consequently, to the reduction of fuel consumption.

\section{Materials and Methods}

Measuring of the impact of the semi-trailer's covering on the amount of fuel consumed was conducted by driving test.

The air resistance depends on the size of the vehicle's frontal area, driving speed, aerodynamic resistance coefficient and on the air density. The relation for calculation of the air resistance in accordance with [18] is as follows:

$$
F_{v}=0,5 \cdot \rho \cdot v^{2} \cdot S
$$

$\rho \quad$ air density $\left[\mathrm{kg}_{\mathrm{g}} \mathrm{m}^{-3}\right]$

$v \quad$ vehicle speed $\left[m . \mathrm{s}^{-1}\right]$

$S \quad$ vehicle frontal area $\left[\mathrm{m}^{2}\right]$

$c_{x} \quad$ air resistance coefficient [-] 
As shown also in the formula 1, the higher air resistance, the higher the driving speed of an articulated vehicle is, since it is squared. The Fig. 2 depicts the common speed driving profile typical for the long-distance goods transport.

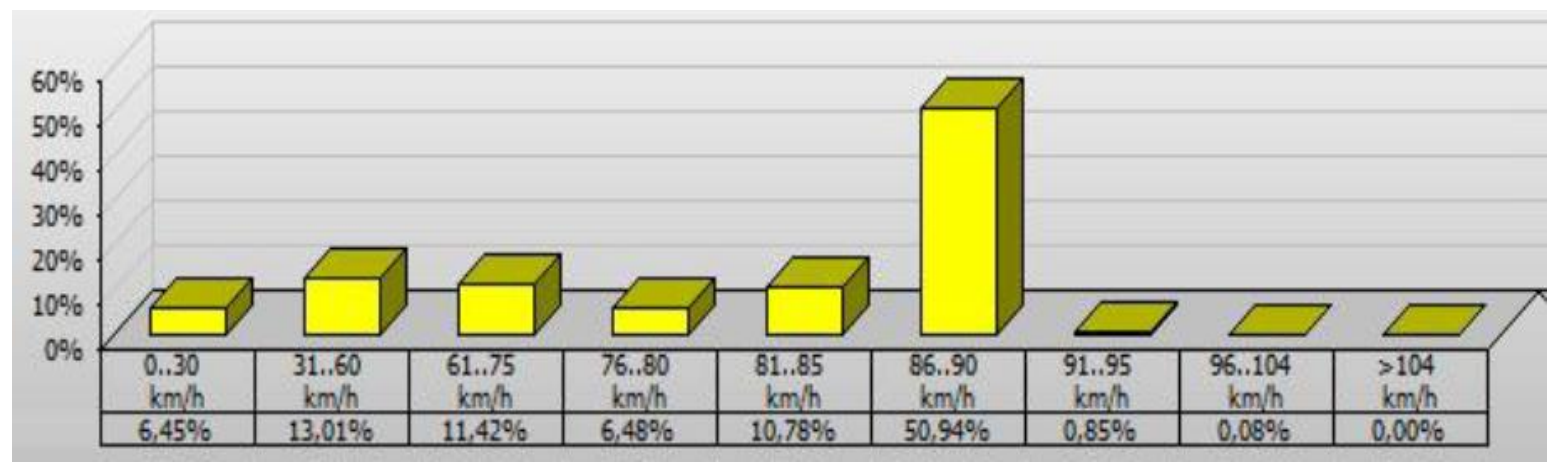

Figure 2: Speed profile of articulated vehicle during the long-distance transport [19]

As seen in the Fig. 2, the articulated vehicle mostly drives at the speeds of $86 \mathrm{~km} \cdot \mathrm{h}^{-1}$ up to 90 $\mathrm{km} . \mathrm{h}^{-1}$ during the long-distance transport. In such speed intervals, the air resistance has a large share on the amount of the fuel consumed, Fig. 1, and, therefore it is necessary to pay attention to reducing the resistance in such type of transport.

The possibilities how to reduce the air resistance of articulated vehicles also lie in their drivers. Concerning the articulated vehicle with tipping semi-trailer designed to carry bulk materials, there is the possibility of covering the loading capacity. The objective of the measurement described in the paper was to find out the impact of covering the empty loading capacity of tipping semi-trailer on the amount of fuel consumed when driving at the stabilised speed of 90 $\mathrm{km} \cdot \mathrm{h}^{-1}$.

\subsection{Articulated vehicle used in the measurement}

The measurement of the impact of covering on the fuel consumption was taken with Renault magnum 460 DXI Euro 5 tractor with Wielton $33 \mathrm{~m}^{3}$ tipping semi-trailer, Fig. 3.

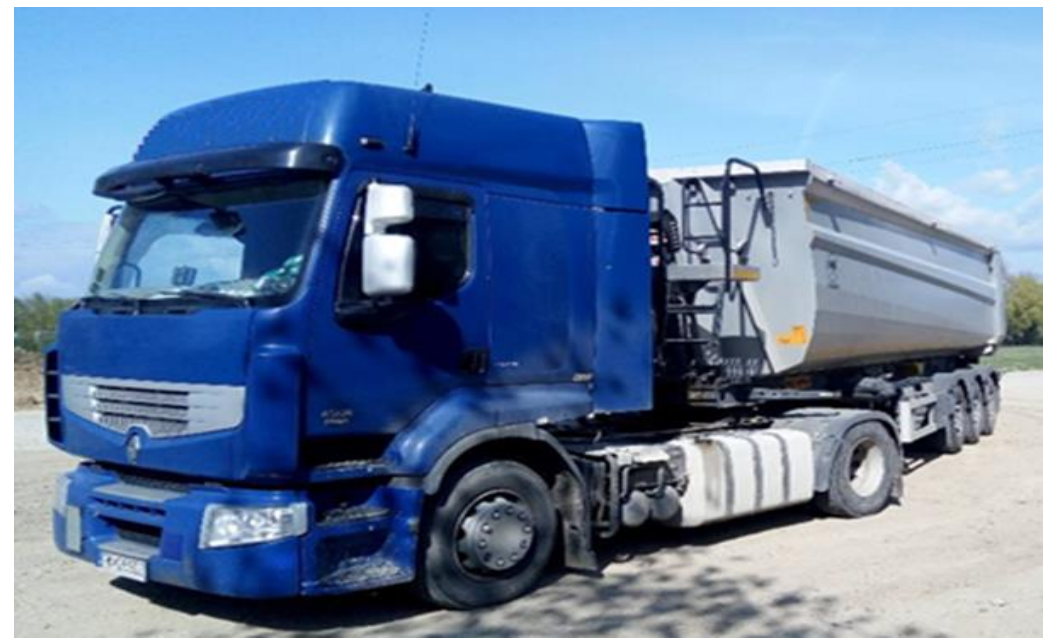

Figure 3: Articulated vehicle used in the measurement [authors] 
Vehicle's technical data are given in the Table 1.

Table 1: Vehicle's technical data

\begin{tabular}{|l|l|}
\hline Engine capacity & $12780 \mathrm{~cm}^{3}$ \\
\hline Engine power & $338 \mathrm{~kW}$ \\
\hline Year of production & 2010 \\
\hline Transmission system & Automatic \\
\hline Tyres & $315 / 80 \mathrm{R} 22,5$ \\
\hline
\end{tabular}

Fig. 4 shows the demonstration of the uncovered semi-trailer and Fig. 5 shows the semi-trailer that is covered.

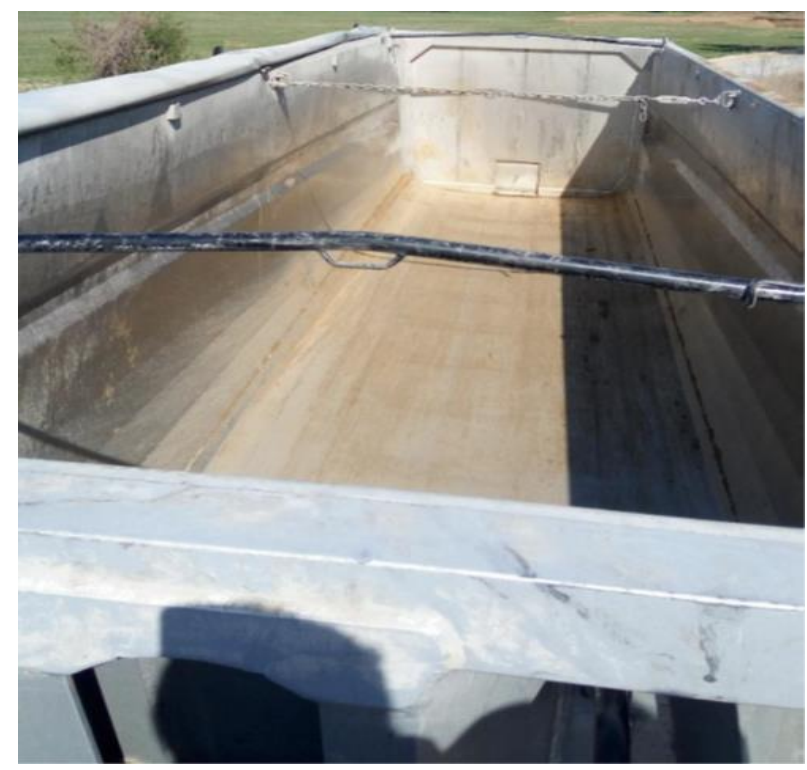

Figure 4: Uncovered loading capacity of tipping semi-trailer [authors]

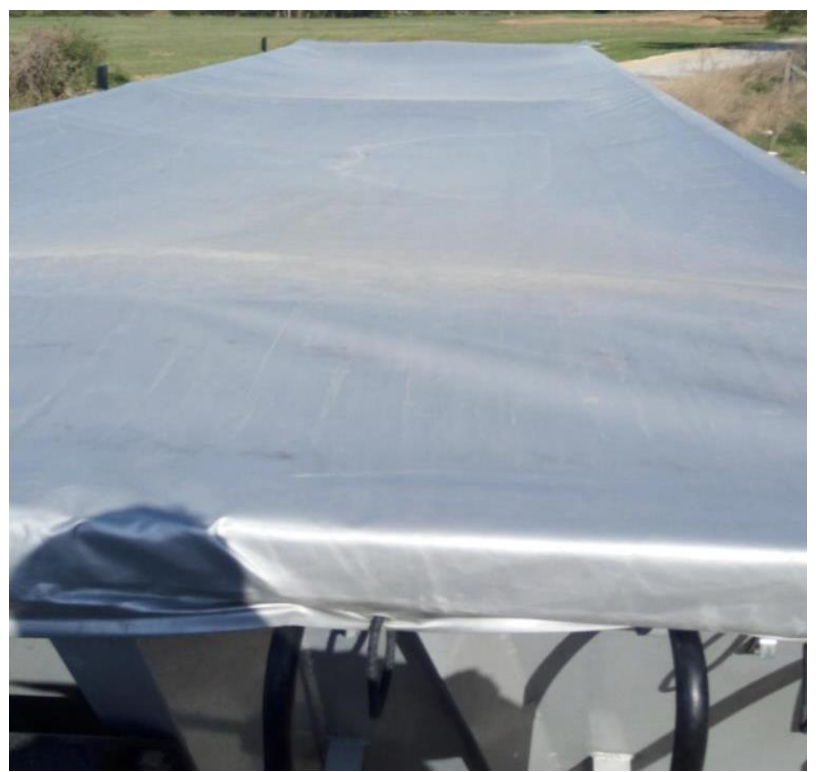

Figure 5: Covered loading capacity of tipping semi-trailer [authors] 


\section{Measurement tools}

The amount of fuel consumed was identified by using of the on-board computer. The accuracy of measurement by the on-board computer was verified by the software that is used to detect the thefts of diesel oil and for creating account book. The on-board computer displays the fuel consumption, the distance travelled and the driving time.

The accuracy of measurement of the driving speed was also verified by the GPS device.

The weather station Irox HRS 70 recorded the pressure of $1,025 \mathrm{hPa}$ and the air temperature from $14^{\circ} \mathrm{C}$ up to $19^{\circ} \mathrm{C}$ during the measurement.

The process of measurement

1) Inspection of the tyre pressure, visual inspection of the technical condition of articulated vehicle.

2) Starting the vehicle to $90 \mathrm{~km} \cdot \mathrm{h}^{-1}$, switching on the cruise control, driving at the constant speed.

3) Measuring at the constant speed.

4) Saving the values measured.

5) The measurement was done 2 times without covering the loading capacity of semi-trailer, Figure 4, and 2 times with having the loading capacity of semi-trailer covered, Figure 5.

\section{Results and Discussions}

The results of the amount of fuel consumed during the driving with uncovered and covered loading capacity are provided in the Table 2 .

Table 2: The impact of uncovering the loading capacity on the fuel consumption

\begin{tabular}{|l|l|}
\hline Loading capacity of semi-trailer & Fuel consumption \\
\hline Uncovered loading capacity & $26.51 .100 \mathrm{~km}^{-1}$ \\
\hline Covered loading capacity & $29.01 .100 \mathrm{~km}^{-1}$ \\
\hline
\end{tabular}

As seen in the Table 1, covering of the loading capacity of tipping semi-trailer led to the reduction of fuel consumption by $2.51 .100 \mathrm{~km} \cdot \mathrm{h}^{-1}$ at the constant speed of $90 . \mathrm{km} . \mathrm{h}^{-1}$ that means $8.1 \mathrm{~kg}$ of $\mathrm{CO}_{2}$ when also taking into account $\mathrm{CO}_{2}$ produced during the diesel oil production per every $100 \mathrm{~km}$ travelled. Having the empty semi-trailer not covered has also an economic impact since there is the fuel cost difference of $2.75 €$ per $100 \mathrm{~km}$ when oil diesel is $1.1 € /$ l. During the driving with uncovered semi-trailer, the air flows into the load area and collides with the rear wall. The rear wall, thus, represents another frontal area. There is also an increase of the air resistance coefficient $c_{x}[20]$. When the semi-trailer is covered, the airflow is stopped and does not collide with the rear part of semi-trailer but flows around its periphery. When assessing, it is necessary to take into consideration the fact that the results were made during driving at the constant speed of $90 \mathrm{~km} \cdot \mathrm{h}^{-1}$. 


\section{Conclusions and Recommendations}

The measurement has highlighted the need of covering the empty semi-trailer before every driving when there is an assumption that the driving would be at the higher speed. The significance of covering the loading capacity increases together with the increase of average driving speed as well as of route length with the empty semi-trailer. It would be appropriate from the carriers to appeal to drivers to cover their semi-trailer before each driving of that kind. The legislative should also be acquainted with such issues since it is needed to look into the possibilities of the regulations of covering the empty semi-trailer when driving on motor and expressways. It would be perfect, although unreachable, to eliminate completely the driving of vehicles with an empty tipping semi-trailer.

\section{Acknowledgements}

This article has been written within the framework of institutional research of PEDAS Faculty of University of Zilina - 7/KCMD/2017 reducing of road vehicles' air resistance and its impact on the environment.

\section{References}

[1] Cecchel, S., Chindamo, D., Turrini, E., et al. „Impact of reduced mass of light commercial vehicles on fuel consumption, CO2 emissions, air quality, and socio-economic costs"2018 In: Scientific of Total Environment. sVol: 613, pp: 409 - 417, DOI: 10.1016/j.scitotenv.2017.09.081

[2] Fontaras, G., Zacharof, NG., Ciuffo, B., „Fuel consumption and CO2 emissions from passenger cars in Europe Laboratory versus real-world emissions“ 2017 In: Progress in Energy and Combustion Science, vol: 60, pp: 97 - 131, DOI: 10.1016/j.pecs.2016.12.004

[3] Gnap, J, Skrúcaný, T. (2014). "Energy Intensity and Greenhouse Gases Production of the Road and Rail Cargo Transport Using a Software to Simulate the Energy Consumption of a Train," Telematics - Support for Transport Communications in Computer and Information Science, pp. 263-272.

[4] Kendra, M., Škorupa, M., Skrúcaný, T., Grenčik, J., Figlus, T. (2017). Comparison of Chosen Environmental Aspects in Individual Road Transport and Railway Passenger Transport. 12th International Scientific Conference of Young Scientists on Sustainable, Modern and Safe Transport High Tatras, Slovakia, pp. 806-811.

[5] A European Strategy for low- emission mobility. https://ec.europa.eu/clima/policies/transport_en 27.september.2017

[6] Modal split of inland freight transport,: http://ec.europa.eu/eurostat/statisticsexplained/index.php/File:Modal_split_of_inland_freight_transport,_2014_(\%25_of_total_inland_ tkm)_YB17.png 27.september.2017

[7] Hanemann, P. et al., „Effects of electric vehicle charging strategies on the German power system“. 2017. In: Applied Energy, Vol:203, ISSN: 0306-2619

[8] Rievaj V.,Synák F. “Does electric car produce emissions?” 2017. In: Scientific Journal of Silesian University of Technology. Series Transport. Vol 94, ISSN: 0209-3324

[9] Wong, VW., Tung, SC., „Overview of automotive engine friction and reduction trends-Effects of surface, material, and lubricant-additive technologies“ 2016, In: Friction. Vol: 4, pp: 1 - 28, DOI: 10.1007/s40544-016-0107-9

[10] Šarkan, B., Stopka, O., Gnap, J., Caban, J. "Investigation of Exhaust Emissions of Vehicles with Spark Ignition Engine within Emission Control," 2016. In: Procedia Engineering, vol. 187, pp. 775-782. 
[11] Duez, B., ,Towards a substantially lower fuel consumption freight transport by the development of an innovative low rolling resistance truck tyre concept" 2016, In: Transport research arena tra2016, vol: 14, pp: 1051 - 1060, DOI: 10.1016/j.trpro.2016.05.175

[12] Sina, N., Nasiri, S., Karkhaneh, V., „Effects of resistive loads and tire inflation pressure on tire power losses and CO2 emissions in real-world conditions" 2015, In: Applied energy, vol: 157, pp: 974 - 983, DOI: 10.1016/j.apenergy.2015.04.010

[13] Suyabodha, A., „A Relationship between Tyre Pressure and Rolling Resistance Force under Different Vehicle Speed“ 2017, In: International Conference on Mechanical, Aeronautical and Automotive Engineering, ICMA, vol: 108, DOI: 10.1051/matecconf/201710812004

[14] Skrúcaný, T., Šarkan, B., Gnap, J., „Influence of Aerodynamic Trailer Devices on Drag Reduction Measured in a Wind Tunnel" 2016, In: Eksploatacja i Niezawadnosc - Maintance and Reliability, vol: 18, pp: 151 - 154, DOI: 10.17531/ein.2016.1.20

[15] Eckert, JJ., Correa, FC., Santiciolli, FM., et al. „Vehicle gear shifting strategy optimization with respect to performance and fuel consumption“" 2014, In: Mechanics Based Design of Structure and Machnies, vol: 44, pp: 123 - 136, DOI: 10.1080/15397734.2015.1094669

[16] Odhams, A., Roebuck, R., Lee, Y., Hunt, S., Cebon, D., "Factors Influencing the Energy Consumption of Road Freight Transport," Proceding of the Institution of Mechanical Engineers Part C - Journal of mechanical Engineering Science, vol. 224(9), pp. 61995-2010.

[17] Current transport data, January 2016. Statisical Office of the Slovak Republic. Transport. Number: 840-0057 / 2016. Code: 061516. Date: March 2016

[18] Skrúcaný, T., Šarkan, B., Gnap, J., "Influence of Aerodynamic Trailer Devices on Drag Reduction Measured in a Wind Tunnel" 2016. In: Eksploatacja I Niezawodnosc - Maintenance and Reliability 2016; 18 (1): 151-154

[19] Internal source: MAN Telematics, telematics software carrier AVE-moto, s.r.o., from 2015

[20] Atiqullah, M., Sanchez, R., Hamler, B., Undergraduate Research on Trailer - Truck Aerodynamic Drag, 2014, In: Proceedings of the Asme International Mechanical Engineering Congress and Exposition, ISBN 978-0-7918-5627-7

\footnotetext{
*Corresponding author.

E-mail address: frantisek.synak@ fpedas.uniza.sk
} 